\title{
A new threat to bees? Entomopathogenic nematodes used in biological pest control cause rapid mortality in Bombus terrestris
}

Alexandrea Dutka, Alison McNulty, Sally M Williamson

There is currently a great deal of concern about population declines in pollinating insects. Many potential threats have been identified which may adversely affect the behaviour and health of both honey bees and bumble bees: these include pesticide exposure, and parasites and pathogens. Whether biological pest control agents adversely affect bees has been much less well studied: it is generally assumed that biological agents are safer for wildlife than chemical pesticides. The aim of this study was to test whether entomopathogenic nematodes sold as biological pest control products could potentially have adverse effects on the bumble bee Bombus terrestris. One product was a broad spectrum pest control agent containing both Heterorhabditis sp. and Steinernema sp., the other product was specifically for weevil control and contained only Steinernema kraussei. Both nematode products caused $\geq 80 \%$ mortality within the 96 hour test period when bees were exposed to soil containing entomopathogenic nematodes at the recommended field concentration of 50 nematodes per $\mathrm{cm}^{2}$ soil. Of particular concern is the fact that nematodes from the broad spectrum product could proliferate in the carcasses of dead bees, and therefore potentially infect a whole bee colony or spread to the wider environment. 


\section{A new threat to bees? Entomopathogenic nematodes \\ used in biological pest control cause rapid mortality in}

\section{Bombus terrestris.}

Alex Dutka, Alison McNulty and Sally M. Williamson*

School of Natural Sciences and Psychology, Liverpool John Moores University, Byrom Street, Liverpool, UK.

*Corresponding author, s.m.williamson@ljmu.ac.uk 


\section{Abstract}

2 There is currently a great deal of concern about population declines in pollinating insects. Many

3 potential threats have been identified which may adversely affect the behaviour and health of

4 both honey bees and bumble bees: these include pesticide exposure, and parasites and pathogens.

5 Whether biological pest control agents adversely affect bees has been much less well studied: it

6 is generally assumed that biological agents are safer for wildlife than chemical pesticides. The

7 aim of this study was to test whether entomopathogenic nematodes sold as biological pest control

8 products could potentially have adverse effects on the bumble bee Bombus terrestris. One

9 product was a broad spectrum pest control agent containing both Heterorhabditis $s p$. and 
10 Steinernema sp., the other product was specifically for weevil control and contained only

11 Steinernema kraussei. Both nematode products caused $\geq 80 \%$ mortality within the 96 hour test

12 period when bees were exposed to soil containing entomopathogenic nematodes at the

13 recommended field concentration of 50 nematodes per $\mathrm{cm}^{2}$ soil. Of particular concern is the fact that nematodes from the broad spectrum product could proliferate in the carcasses of dead bees, and therefore potentially infect a whole bee colony or spread to the wider environment.

\section{Background}

In recent years there has been much concern about threats to pollinating insects such as bees. The exact extent of bee decline, particularly for wild pollinators, is unknown; and the cause of bee decline is most likely to be multifactorial. Along with habitat loss, major threats to bees which have been subject to scientific study include pesticides and pathogens.

The effects of pesticides on both honey bees and bumble bees have been extensively researched, with adverse behavioural effects of neonicotinoids being observed in the laboratory (Williamson et al., 2014; Williamson and Wright, 2013), and semi-field and field studies reporting similar adverse effects at a colony level (Feltham et al., 2014; Gill et al., 2012; Goulson, 2015). Many studies of bee pathogens have focused on the honeybee Apis mellifera, as disease processes are a possible contributing factor to colony collapse disorder, the phenomenon of increased bee colony losses reported by commercial apiarists (Cornman et al., 2012). Varroa destructor, a parasitic mite, is a major threat to honeybee health, and also acts as a vector for viral pathogens such as deformed wing virus (Rosenkranz et al., 2010). The microsporidian parasite Nosema ceranae has also been identified as a potential threat to honey bee health, with pesticide exposed bees 
32 becoming more susceptible to this pathogen (Pettis et al., 2012). Wild pollinators can also be

33 affected by some of the same pathogens as honeybees, including $N$. ceranae and deformed wing

34 virus (Arbulo et al., 2015; Genersch et al., 2006).

35 Much less attention has been given to potential adverse effects of biological pest control agents

36 on bees, and it is generally assumed that integrated pest management strategies which employ

37 biological pest control agents are safer for bees and other wildlife than chemical pesticides

38 (Furlan and Kreutzweiser, 2015). A few studies which have directly tested biological pest control

39 products on bees have reported that certain biological agents, such as Bacillus thuringiensis, and

40 a recombinant protein derived from spider venom toxin, are relatively safe for bees (Mommaerts

41 et al., 2010; Nakasu et al., 2014). However, biological agents are unpredictable: deliberately

42 introduced predators and pathogens may also have off-target effects, and potentially harm

43 wildlife (Coote, 2003; Kaiser, 2015). Many biological pest control agents remain less tightly

44 regulated than chemical pesticides, and can be bought from online retailers for unrestricted use in

45 gardens or in agriculture. Among these products, entomopathogenic nematodes are widely used

46 for the control of a broad range insect pests (Dillman and Sternberg, 2012). Entomopathogenic

47 nematodes used in pest control often exhibit a symbiotic relationship with certain bacteria: on

48 entering the host insect, pathogenic bacteria are released by the parasite, and it is bacterial infection which causes the insect's death (Dillman and Sternberg, 2012). The bacterial symbiont

50 is Photorhabdus in nematodes of the genus Heterorhabditis, and Xenorhabdus in nematodes of

51 the genus Steinernema. The bacterial symbionts must perform 3 separate tasks to allow

52 successful proliferation of the nematodes within the insect host: these are to overcome insect

53 immune defences and cause septicaemia and death; to break down the tissues of the dead insects

54 to release nutrients for the nematodes to proliferate; then to successfully recolonise the infective 
55 juvenile nematodes which will then be released (Goodrich-Blair and Clarke, 2007). All these

56 tasks must be successfully achieved to allow nematode proliferation in an insect host, though

57 only the first is necessary to cause insect death of a non-viable host insect (Nielsen-LeRoux et al.

58 2012).

59 The aim of this investigation was to determine whether entomopathogenic nematodes

60 (Steinernema spp. and Heterorhabditis sp.) marketed commercially as biological pest control

61 agents for use in organic farming, and advertised as being safe for wildlife, had any detrimental

62 effects on individual Bombus terrestris when applied to soil at the manufacturer's recommended

63 concentration and below.

Materials and Methods

Bumblebees Bombus terrestris were obtained as commercially reared colonies from Koppert.

Bees were maintained within the hive, and were not permitted free flight outdoors, to avoid any incidental pathogen exposure. 2 colonies were used during the course of the experiments described, which were performed from June to July 2015.

Entomopathogenic nematodes were obtained as commercially available mixtures from the Nemasys range marketed by BASF. The products used were "Grow Your Own" (abbreviated to GYO in this article) consisting of a mixture of Heterorhabditis sp. and Steinernema spp., and "Vine Weevil Killer" (abbreviated to VW in this article) containing Steinernema kraussei. The exact composition and species mixture contained in the GYO product was proprietory and not disclosed by the manufacturer. 2 containers of each nematode product, from 2 separate batches, were used during the course of the study. 
77 Individual bees were captured at the hive entrance and cold anaesthetised to facilitate transfer into the treatment boxes. The treatment boxes were 0.7 litre plastic boxes fitted with feeding tubes containing 50\% sucrose solution. Each box contained a $2 \mathrm{~cm}$ depth of sterile soil. Each bee was housed individually throughout the nematode exposure treatment. Nematodes were rehydrated and diluted according to the manufacturer's directions, and were applied to the soil in the treatment boxes at the manufacturer's recommended concentration of 50 nematodes per $\mathrm{cm}^{2}$, and at the lower concentrations of 25 nematodes per $\mathrm{cm}^{2}$ and 10 nematodes per $\mathrm{cm}^{2}$. In the controls, the soil was treated with an equivalent volume of distilled water. Bee mortality was measured 24, 48 and 72 and 96 hours after nematode exposure.

The duration of the experiments described here was 4 weeks in total, with the experimental procedure being repeated on different individual bees each week. One bee colony and batch of nematode products was used for the first 2 weeks, and a second colony and batch of each nematode product being used in the second 2 weeks. Each week, 5 individual bees were included in each treatment group; therefore 20 individual bees, 10 from each colony, were exposed to each treatment in total.

Carcasses of bees which died during the nematode exposure treatment were transferred to white traps (White, 1927) to allow the collection of any nematodes which proliferated in the infected bee carcass. Any nematodes proliferating in the bee carcasses were quantified after 4-5 weeks. White traps which had become dry, or which had become overgrown with mould, were not included. Nematode counts were performed by counting the number of individual nematodes in 3 $\mathrm{x} 50 \mu 1$ aliquots of culture liquid, then adjusting this for the total volume of culture liquid to estimate the total number of nematodes produced from each individual infected bee. Control bee carcasses were also collected and transferred to White traps, though these were fewer in number 
100 as there was little mortality during the experimental procedure: however, some control bees were 101 maintained within their boxes until they died, which was usually after 7 to 10 days, specifically

102 for this purpose, providing White trap data for 10 individual control bees from each hive.

$118<0.001)$

\section{Results}

Data was analysed using SPSS; a Kaplan-Meier survival analysis was performed on the mortality data, and a Kruskall-Wallis test was performed on the white trap data of recovered nematodes.

\section{Mortality of Bombus terrestris exposed to entomopathogenic nematodes}

Both commercially available nematode products rapidly killed bees, with the first incidences of mortality being observed after 48 hours of nematode exposure (Figure 1). All concentrations of the GYO nematodes caused significantly more mortality than occurred in the control group (10 nematodes per $\mathrm{cm}^{2}, \chi_{3}^{2}=60.1, \mathrm{p}<0.001 ; 25$ nematodes per $\mathrm{cm}^{2}, \chi_{3}^{2}=51.7, \mathrm{p}<0.001 ; 50$ nematodes per $\left.\mathrm{cm}^{2}, \chi_{3}^{2}=51.2, \mathrm{p}<0.001\right)$. There was no difference in mortality between the different nematode concentration treatment groups. All concentrations of the VW nematodes also caused significantly more mortality than occurred in the control group (10 nematodes per $\mathrm{cm}^{2}$, $\chi_{3}^{2}=17.5, \mathrm{p}<0.001 ; 25$ nematodes per $\mathrm{cm}^{2}, \chi_{3}^{2}=34.6, \mathrm{p}<0.001 ; 50$ nematodes per $\mathrm{cm}^{2}, \chi_{3}^{2}=$ $51.3, \mathrm{p}<0.001)$. In this case mortality was affected by nematode concentration: exposure to 50 nematodes per $\mathrm{cm}^{2}$ caused higher mortality than exposure to 10 nematodes per $\mathrm{cm}^{2}\left(\chi_{3}^{2}=12.4, \mathrm{p}\right.$

\section{Nematode proliferation in infected bee carcasses}


120 There was a notable difference in the ability of the two different entomopathogenic nematode

121 products to proliferate in the carcasses of infected bees. $B$. terrestris proved a viable host for the

122 entomopathogenic nematode species contained in the GYO product, and every nematode

123 exposed bee carcass investigated had allowed a substantial number of infective juvenile

124 nematodes to develop (see Table 1). There was no difference in nematode proliferation between

125 the different nematode concentration treatment groups for the GYO product $\left(\chi_{2}^{2}=3.26, p=\right.$

126 0.196). In contrast to this, B. terrestris does not appear to be a viable host for the proliferation of

127 S. kraussei, the infective agent in the VW product. Only 6 out of 48 bees which had died during

128 the nematode exposure treatment yielded any infective juvenile nematodes at all, too few to

129 compare nematode yield between different treatment groups. The control bee carcasses from

130 both experiments which had died incidentally or been euthanised at the end of the study yielded

131 no nematodes $(\mathrm{n}=20)$, suggesting that the $B$. terrestris used in this study did not naturally host

132 any nematode parasites.

Discussion

The results we present here show that the native British bumble bee $B$. terrestris is remarkably susceptible to two commercially available entomopathogenic nematode pest control products.

137 Both products caused very high levels of bee mortality after only 72 hours of exposure, with the

138 first deaths evident after 48 hours. This result was unexpected: the susceptibility of bees to entomopathogenic nematodes such as Heterorhabdidtis spp. and Steinernema spp. has never

140 previously been reported. 
141 The differences in nematode proliferation within the infected bee carcasses were also notable,

142 with Steinernema kraussei failing to proliferate well in bee carcasses, while the product

143 containing a mixture of Heterorhabditis and Steinernema species resulted in thousands of

144 infective juveniles emerging from the bumble bee host. This may suggest that Heterorhabditis

145 was the primary nematode proliferating within the bee carcasses, and the size of the nematodes

146 recovered would to some extent support this; however without definitive genetic tests to

147 determine the species recovered, and indeed the exact species mix within the GYO product, this

148 remains speculative. Future studies using pure Heterorhabditis cultures would certainly help to

149 confirm or refute this preliminary observation. It is possible that the bacterial symbiont of

150 Steinernema species, Xenorhabdus, is able to overcome the bee immune defences and cause

151 septicaemia, but is unable to sufficiently break down the tissues to allow nematode feeding and

152 proliferation; whereas Photorhabdus, the bacterial symbiont of Heterorhabditis, may be able to

153 digest the bee tissues more effectively and provide a better supply of nutrients to the nematodes

154 (Nielsen-LeRoux et al. 2012). Alternatively, it is possible that as a parasite strain selected and

155 maintained by the manufacturer for its pathogenicity of weevils, this particular isolate of S.

156 karussei was less able to proliferate in a hymenopteran host.

157 This difference in proliferation, if confirmed in a field setting, has obvious implications for how

158 ecologically significant the susceptibility of $B$. terrestris to entomopathogenic nematodes may

159 be. Exposure to $S$. kraussei may kill individuals, but without any proliferation and release of

160 infective juveniles then this species of nematode would only impact bees directly in contact with

161 the initial application. However, the implications of entomopathogenic nematode sold as crop

162 protection products being able to proliferate within $B$. terrestris as a viable host suggests this

163 poses a greater risk of whole colonies becoming infected after a single individual exposure. 
164 The fossorial habits of $B$. terrestris, and the overwintering of queens underground, may make

165 this species uniquely vulnerable to biological pest control agents applied directly to the soil.

166 Evidence from studies on the relative suspeptibility of pest species to entomopathogenic

167 nematodes have shown that the lepidopteran Cydia latiferreana, a pest of hazelnuts which

168 overwinters in soild or leaf litter as a pupa, is far more susceptible to nematode infection than a

169 weevil pest of the same crop which has little contact with the soil (Chambers et al. 2010).

170 Although we acknowledge that this is a laboratory study and may not be directly applicable to a

171 field setting, it highlights the need for further research into the off-target effects of biological

172 pest control agents on insect pollinators. The conclusions of scientists advising the European

173 regulatory body OECD in 1996 were that entomopathogenic nematodes were safe for wildlife

174 and should not be regulated (Ehlers and Hokkanen, 1996). However, the main justification for a

175 lack of regulation appears to be based on the premise that as multicellular animals, nematodes

176 could not be regulated in the same way as entomopathogenic bacterial products such as Bacillus

177 thuringiensis, and should instead only be regulated as introduced species if they are applied

178 outside their country of origin (Ehlers and Hokkanen, 1996). The ideas underpinning the

179 definition of entomopathogenic nematodes being safe for wildlife included the following: they

180 pose no threat to mammals and birds (Boemare et al. 1996); they have minimal adverse effects

181 on above ground non-target invertebrates; (Akhurst 1990) and they do not disperse widely in the

182 environment (Downes and Griffin 1996). Evidence of the effects of entomopathogenic

183 nematodes applied directly to soil on non-target soil-dwelling invertebrates is lacking, and does

184 not seem to have been included in these safety assessments.

185 Compared with other pathogen types, nematodes able to parasitise bees do not appear to be very

186 diverse, or very well studied. Bombus spp. may be naturally infected by the parasitic nematode 
187 Sphaerularia bombi, which parasitises hibernating queens (Rutrecht and Brown, 2008), but a

188 search of the literature reveals no other parasitic nematodes associated with bumblebees.

189 Certainly, there is little evidence yet that nematode parasites used in pest control are infecting

190 bumble bees in the field; but then it would appear that very few studies have been undertaken

191 which would reveal the extent of such a phenomenon. What is evident from the literature is that

192 several other introduced pathogens and parasites do in fact pose a serious threat to wild

193 bumblebees: parasitic mites, Nosema spp., Crithidia bombi, neogregarine parasites, and several

194 viruses including deformed wing virus, are all pathogens which are believed to have spread to

195 wild bees from commercial bee rearing activities (Meeus et al., 2011). A degree of caution may

196 therefore be advisable when deliberately introducing insect pathogens to the environment as

197 biological pest control agents, until more is known about their effects on beneficial arthropods.

References

Arbulo, N., Antunez, K., Salvarrey, S., Santos, E., Branchiccela, B., Martin-Hernandez,

R., Higes, M. and Invernizzi, C. (2015). High prevalence and infection levels of Nosema ceranae in bumblebees Bombus atratus and Bombus bellicosus from Uruguay. J Invertebr Pathol.

Akhurst, R.J. (1990). Safety to non target invertebrates of nematodes of economically important pests, p.233-240. In L.A.L. Laird \& E.W. Davidson (eds.), Safety of microbial insecticides. Boca Raton, CRC Press

Boemare, N.E., Laumond, C. and Mauleon, H. (1996). The entomopathogenic nematode- 
208 Chambers, U., Bruck, D.J., Olsen, J., and Walton V.M. (2010). Control of overwintering

209 filbertworm (Lepidoptera: Tortricidae) larvae with Steinernema carpocapsae. J Econ Entomol.

210 103(2):416-22.

211 Coote, T. a. L., E. (2003). From 61 species to five: endemic tree snails of the Society Islands fall

212 prey to an ill-judged biological control programme. Oryx 37, 91-96.

213 Cornman, R. S., Tarpy, D. R., Chen, Y., Jeffreys, L., Lopez, D., Pettis, J. S., vanEngelsdorp, D.

214 and Evans, J. D. (2012). Pathogen webs in collapsing honey bee colonies. PLoS One 7, e43562.

215 Dillman, A. R. and Sternberg, P. W. (2012). Entomopathogenic nematodes. Current Biology 22,

216 R430-R431.

217 Downes, M.J. \& C.T. Griffin. 1996. Dispersal behaviour and transmission strategies of the

218 entomopathogenic nematodes Heterorhabditis and Steinernema. Biocontrol Sci. Technol. 6: 347219356.

Ehlers, R. U. and Hokkanen, H. M. T. (1996). Insect biocontrol with non-endemic

entomopathogenic nematodes (Steinernema and Heterorhabditis spp): Conclusions and

recommendations of a combined OECD and COST Workshop on Scientific and Regulatory

223 Policy Issues. Biocontrol Science and Technology 6, 295-302.

225 Feltham, H., Park, K. and Goulson, D. (2014). Field realistic doses of pesticide imidacloprid

226 reduce bumblebee pollen foraging efficiency. Ecotoxicology 23, 317-23.

227 Furlan, L. and Kreutzweiser, D. (2015). Alternatives to neonicotinoid insecticides for pest

228 control: case studies in agriculture and forestry. Environ Sci Pollut Res Int 22, 135-47. 
229 Genersch, E., Yue, C., Fries, I. and de Miranda, J. R. (2006). Detection of Deformed wing virus,

230 a honey bee viral pathogen, in bumble bees (Bombus terrestris and Bombus pascuorum) with

231 wing deformities. J Invertebr Pathol 91, 61-3.

232 Gill, R. J., Ramos-Rodriguez, O. and Raine, N. E. (2012). Combined pesticide exposure severely 233 affects individual- and colony-level traits in bees. Nature 491, 105-8.

234 Goodrich-Blair, H., and Clarke, D.J. (2007). Mutualism and pathogenesis in Xenorhabdus and 235 Photorhabdus: two roads to the same destination. Mol Microbiol. 64, 260-268

236 Goulson, D. (2015). Neonicotinoids impact bumblebee colony fitness in the field; a reanalysis of 237 the UK's Food \& Environment Research Agency 2012 experiment. PeerJ 3, e854.

238 Kaiser, J. M., and Heimpel, G.E. (2015). Linking risk and efficacy in biological control host239 parasitoid models Biological Control 90, 49-60.

240 Meeus, I., Brown, M. J. F., De Graaf, D. C. and Smagghe, G. (2011). Effects of Invasive

241 Parasites on Bumble Bee Declines. Conservation Biology 25, 662-671.

242 Mommaerts, V., Jans, K. and Smagghe, G. (2010). Impact of Bacillus thuringiensis strains on 243 survival, reproduction and foraging behaviour in bumblebees (Bombus terrestris). Pest Manag 244 Sci 66, 520-5.

245 Nakasu, E. Y., Williamson, S. M., Edwards, M. G., Fitches, E. C., Gatehouse, J. A., Wright, G. 246 A. and Gatehouse, A. M. (2014). Novel biopesticide based on a spider venom peptide shows no 247 adverse effects on honeybees. Proc Biol Sci 281. 
248 Nielsen-LeRoux, C., Gaudriault, S., Ramarao, N., Lereclus, D., and Givaudan, A. (2012). How

249 the insect pathogen bacteria Bacillus thuringiensis and Xenorhabdus/Photorhabdus occupy their 250 hosts. Curr Opin Microbiol 15(3) 220-231.

251 Pettis, J. S., vanEngelsdorp, D., Johnson, J. and Dively, G. (2012). Pesticide exposure in honey

252 bees results in increased levels of the gut pathogen Nosema. Naturwissenschaften 99, 153-8.

253 Rosenkranz, P., Aumeier, P. and Ziegelmann, B. (2010). Biology and control of Varroa

254 destructor. J Invertebr Pathol 103 Suppl 1, S96-119.

255 Rutrecht, S. T. and Brown, M. J. F. (2008). The life-history impact and implications of multiple 256 parasites for bumble bee queens. International Journal for Parasitology 38, 799-808.

257 White, G. F. (1927). A Method for Obtaining Infective Nematode Larvae from Cultures. Science $25866,302-3$.

259 Williamson, S. M., Willis, S. J. and Wright, G. A. (2014). Exposure to neonicotinoids influences 260 the motor function of adult worker honeybees. Ecotoxicology 23, 1409-18.

261 Williamson, S. M. and Wright, G. A. (2013). Exposure to multiple cholinergic pesticides impairs 262 olfactory learning and memory in honeybees. J Exp Biol 216, 1799-807 
Figure 1: Mortality of Bombus terrestris exposed to entomopathogenic nematodes.

Significant levels of mortality were observed in bees exposed to both the GYO product containing Heterorhabditis sp. and Steinernema sp.(A-C), and the VW product containing Steinernema kraussei (D-F). Mortality was recorded after 24, 48, 72 and 96 hours of nematode exposure, though no mortality was observed after 24 hours. Nematodes were applied to soil at the following concenrations: control (no nematodes; vertical striped bars; $n=20$ control bees for each nematode product tested), 10 nematodes per $\mathrm{cm}^{2}$ (dotted bars; $\mathrm{n}=20$ bees for each nematode product tested ), 25 nematodes per $\mathrm{cm}^{2}$ (diagonal striped bars bars; $\mathrm{n}=20$ bees for each nematode product tested), and 50 nematodes per $\mathrm{cm}^{2}$ (checkered bars; $\mathrm{n}=20$ bees for each nematode product tested). Bar charts show mean (+/- SE) percentage mortality.
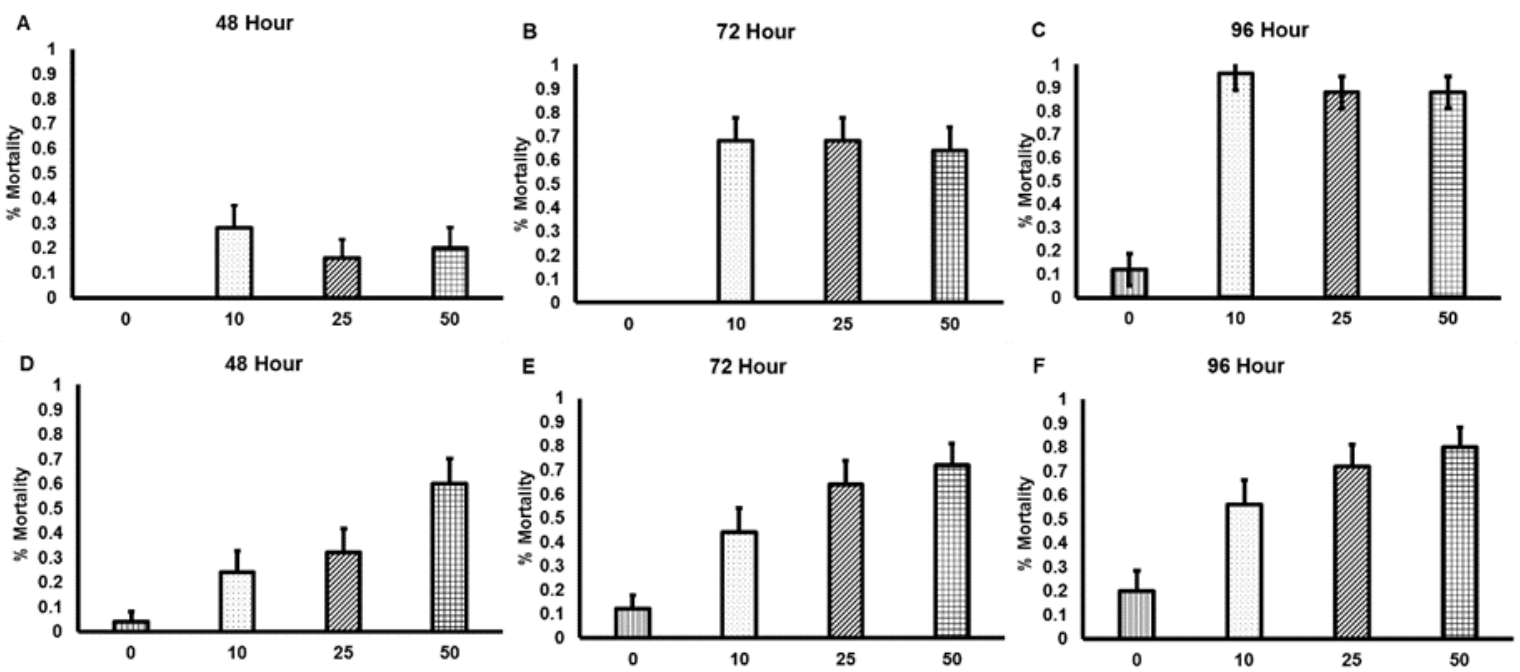
Table 1: Nematode proliferation in the carcasses of bees which died during the nematode exposure experiment.

\begin{tabular}{|l|l|l|l|l|l|l|}
\hline $\begin{array}{l}\text { Nematode } \\
\text { product } \\
\text { bees were } \\
\text { exposed to }\end{array}$ & $\begin{array}{l}\text { Nematode } \\
\text { exposure } \\
\text { (nematodes } \\
\text { per } \mathrm{cm}^{2} \\
\text { soil) }\end{array}$ & $\begin{array}{l}\text { Number } \\
\text { of } \\
\text { carcasses } \\
\text { studied }\end{array}$ & $\begin{array}{l}\text { Number of } \\
\text { carcasses } \\
\text { with } \\
\text { nematodes }\end{array}$ & $\begin{array}{l}\text { Median } \\
\text { number of } \\
\text { nematodes } \\
\text { per carcass }\end{array}$ & $\begin{array}{l}\text { Lowest } \\
\text { number } \\
\text { recovered }\end{array}$ & $\begin{array}{l}\text { Highest } \\
\text { number } \\
\text { recovered }\end{array}$ \\
\hline Control & 0 & 10 & 0 & 0 & 0 & 0 \\
\hline GYO & 10 & 12 & 12 & 9750 & 1950 & 18750 \\
\hline GYO & 25 & 17 & 17 & 7200 & 2700 & 12500 \\
\hline GYO & 50 & 16 & 16 & 7750 & 4800 & 57750 \\
\hline Control & 0 & 10 & 0 & 0 & 0 & 0 \\
\hline VW & 10 & 13 & 2 & 0 & 0 & 53760 \\
\hline VW & 25 & 17 & 3 & 0 & 0 & 6800 \\
\hline VW & 50 & 18 & 1 & 0 & 0 & 3600 \\
\hline
\end{tabular}


